\title{
Managerial Communication in the Vision of Hunedoara County Managers
}

\author{
Nicolae Tașcă ${ }^{1, *}$, Nicu-Pantelimon Rotaru ${ }^{1}$, and Lucian Lupu-Dima ${ }^{2}$ \\ ${ }^{1}$ University of Petroșani, 332006 Petroșani, Romania \\ ${ }^{2}$ Mining Engineering, Surveying and Construction Department, University of Petroșani, $332006{ }^{*}$ \\ Petroșani, Romania
}

\begin{abstract}
The aim of the paper is to analyse the managers and business owners' vision Hunedoara County from a managerial communication perspective, depending on the age on the market, as well as the turnover. The study is based on a questionnaire containing 14 questions, distributed online, and applied to a group of over 500 companies in Hunedoara County between September 13, 2020 - September 30, 2020. We received answers from 34 companies, which are the basis of the research. Our research revealed some expressive data on the act of managerial communication, depending on the turnover of the companies, the way of exercising the communication, as well the managers and business owners' vision how managerial communication influences the success of companies. The respondents, as mentioned, come only from the companies of Hunedoara county, but the study can be extrapolated to provide an image for all Romanian companies, as the authors show in the paper. The paper creates an image of the managers and business owners' vision about managerial communication, showing that it must be decentralized to managers or communication specialists, especially since many respondents claim that the success of companies is influenced by managerial communication. This study can be a contribution to managerial communication, allowing managers and business owners to improve their vision of communication, and the companies they run to be more successful.
\end{abstract}

\section{Introduction}

Authors, analysing the field of managerial communication, found that managerial communication or public relations have a very old existence in Europe [1]. Different sources give different years regarding the beginning of managerial communication. However, everything converges towards the same image, the seniority of this field does not decrease in less than a century. In Eastern Europe, this concept emerged at a significant distance after the fall of the communist regime and is not yet fully integrated into the organizational cultures of many companies or management baggage. While in Western European companies there are departments consisting of communication specialists, in Eastern Europe and mainly in Romania such departments are quite rare, and the existence

* Corresponding author: author@email.org 
of such specialists in the field in companies is an exception, as you can see in this paper. One explanation could be the preponderance of small companies, which are generally run by their owners and which still show a centralized way of managing business, which is also found in managerial communication.

\section{Research problem}

In Europe, managerial communication has a history of at least a century. Bentele and Szyska refer to Krups as the first company with a press department, founded in 1870 . L'Etang talks about the beginning of public relations in England in the 1920s. appeared in the early twentieth century, the industry is much older. Managerial communication is widely practiced in Europe, although rarely under this name. Due to all kinds of societal, economic and technological reasons, executives have become increasingly aware that public acceptance and trust in their companies is a fundamental condition for the survival of the organizations they lead. This role belongs to trade and other groups (internal and external) but also to public opinion as a whole [1].

Managerial communication is the communication of managers on various levels with various target groups, internal and external. These groups can be single employees, entire departments, or the public in general. For some managers, management communication is whatever the communications department does: internal and external communication, company communication, marketing communication, corporate communication, sponsoring, investor relations, job market communication, issues management, even public relations.

Managerial communication is all the communication managers have do to communicate effectively in their organisations: from the individual to the corporate level. From traditional written and spoken forms to computer graphic-generated presentations, from email to press conferences and web pages on the internet, the effective manager must communicate concisely and clearly. While the number of channels for communication in business rapidly increases, the ability to persuade and motivate has never been more important. Each manager and every company have a story to tell - management communication makes sure that story becomes a competitive advantage [2].

Managerial communication fulfils the following communication functions:

- informational function - monitoring internal and external information obtained by all possible means;

- command and training function - to ensure unity and continuity for the team's actions in the direction of the established objectives;

- the function of influencing and convincing, guiding and advising - of control over the employee's information and behaviour;

- the function of integration and maintenance of information - ensures the efficiency of the activity organization. To perform these functions, the manager has a few ways and various communication systems. One of his tasks is to permanently streamline intra and interorganizational communication. According to studies conducted in organizations in performing countries a successful manager dedicates between 55 and $95 \%$ of his time to communication activities. On average, a manager uses over $70 \%$ of his time to speak, listen, write, and read, so as to communicate. This weight differs depending on the hierarchical position of the manager [3].

Within companies, communication pursues 3 major objectives:

- To build a strong and well-valued identity;

- To contribute to the emergence of a new work management;

- To participate in the modernization of production and production structures [4]. 
Communication means almost everything in management, if the quality of communication depends on understanding the problems any employee may deal with, from manager to clerk at the lowest hierarchical level, the durability of relationships between them, the manager's ability to motivate and to lead its subordinates, but also the relationship with the external environment of the organization from which very useful information is taken for its good functioning are taken [5].

In order to have a more accurate image, we researched the situation of managerial communication in other countries in Southeast Europe, an area that also includes Romania.

In Bulgaria, those involved in public relations activities in non-governmental organizations are mainly young people without training in public communication. This was the result of a single survey conducted in 1999. These young people between the ages of 20 and 30 are mostly in this business for up to three years, $65.5 \%$ have a degree in journalism and $32 \%$ have a degree in philology. In terms of interests, $58 \%$ said that creating images is a priority in their service, while $33.3 \%$ mentioned professional consultations and the development of communication strategies in private companies. This interpretation of the professional responsibilities of public relations experts is typical for both for them and journalists. Almost $30 \%$ of journalists claim that the main activity of a private public relations agency involves "collecting accurate and authentic information and presenting it to the media." Much more serious is the problem of not understanding the importance of public relations activities on the part of company managers. This lack of corporate culture leads to the irrational and inefficient use of public relations experts in corporate activities and causes problems in communication between organizations and their public [1].

Managerial communication in Hungary is practiced as a strategic activity. This profession requires a deeper understanding, both by company management and by the public, and it is important to create master's and Ph.D. programs. education. The authors considered that it was too early to talk about professionalism, but Hungary took the first steps on the long road to professionalism. Openness to the long tradition (over a century) and the experiences of Western practitioners could help shorten this difficult path [1].

Marcel Pikhart and Blanka Klimova researched the importance of business and managerial communication in another Eastern European country, the Czech Republic. In their interviews with the managers of the Czech SMEs managers surveyed, they found that neither business nor managerial communication is sufficiently and intentionally managed in these SMEs. The managers, owners or shareholders of these SMEs do not consider that a communication strategy is very important and do not follow any strategies to optimize business and managerial communication [6].

In the last year, managerial communication has also been affected by the COVID-19 pandemic. For this reason, we have added papers on this topic to our theoretical research. James K. C. Chen and Thitima Sriphon investigated how remote work influenced the relationship between managers and employees and found that there is a lack of trust between managers and employees. Managers disagree with their employees working remotely and they try to control and monitor employees more closely than they did before COVID-19, and this leads employees to the employees discomfort. Command and control of management without consultation or collaboration is detrimental to collaborative work and team relationships, and a lack of trust leads to a negative outcome of organizational performance [7].

\section{Research methodology}

The authors initiated a study based on a questionnaire consisting of 14 questions. This questionnaire was distributed online and was applied to a group of over 500 companies in Hunedoara County between September 13, 2020 - September 30, 2020. The group of over 
500 companies was selected according to the national structure, by respecting the division into small companies (with an annual turnover of less than EUR 2 million) and medium and large companies, as presented in the White Paper on SMEs in Romania 2020 [8]. Thirtyfour companies responded to the authors' request and these answers form the basis of the research.

The respondents, as mentioned, come only from companies in Hunedoara County. Because the structure of respondents respects the characteristics of the economy of the entire country in terms of the preponderance of small enterprises (over $80 \%$ being SMEs), the result of the study has a degree of representativeness and can provide an image of managerial communication in Romanian companies.

After receiving the reviews, between April 26 and 28, we conducted an interview with the manager of a company that has not answered the questions so far. His answers overlapped $95 \%$ with what our study showed, which confirms that the study is representative, even if its limitations are relevant.

\section{Interpretation of research results}

The study conducted by the authors analyses the managerial communication in companies from Hunedoara county, both in terms of its exercise and in terms of two important elements related to the existence of companies. It is about the duration of their existence on the market, as well as about the turnover or the number of existing managers in companies.

After collecting the answers, it was found that most companies have a market presence between 21 and 30 years (37.5\%). A percentage with a similar value is found in companies with an existence between 10 and 20 years (34.4\%), and the "youngest" companies account for only $28.1 \%$ " (Fig. 1).

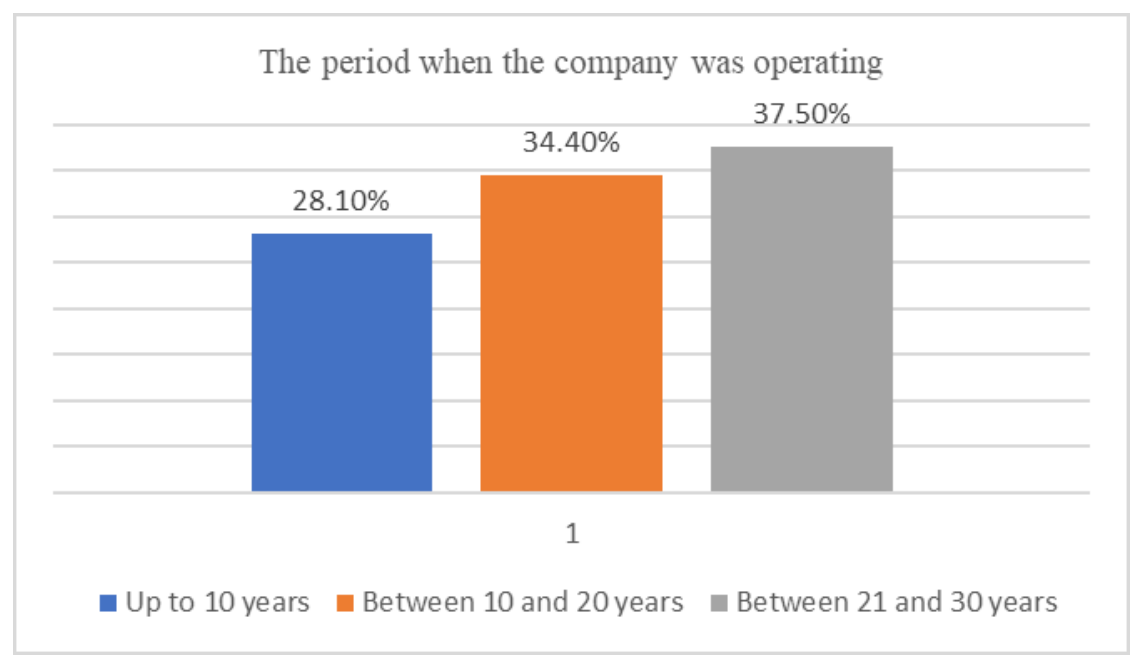

Fig. 1. The period when the company was operating.

Although the percentage of companies with a long existence on the market is high, in terms of annual turnover things are completely different. Almost $70 \%$ of companies have an annual turnover of less than 1 million euros. It is followed, equally, by $12.5 \%$, of both those with an annual turnover of between 1 and 2 million euros and between 2.1 and 5 million euros. Only $6.2 \%$ of companies have turnovers between 5.1 and 10 million euros (Fig. 2). 


\section{The Company's annual turnover}

\section{$68.80 \%$}

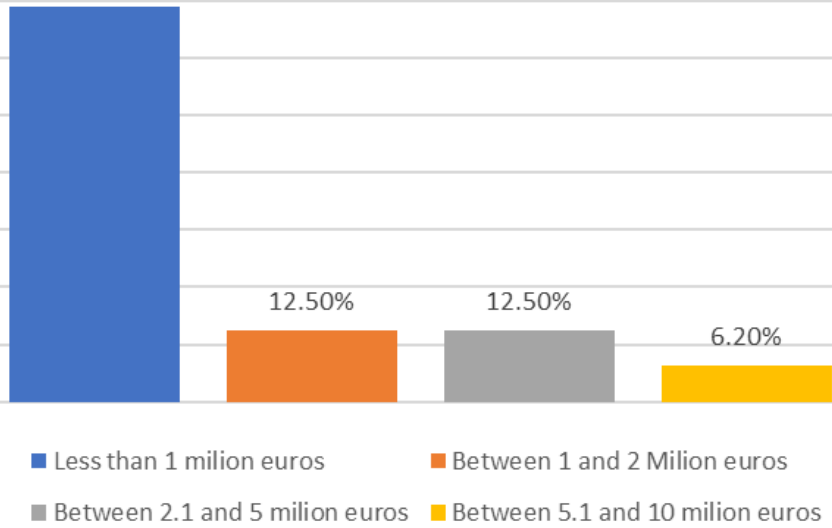

Fig. 2. The company's annual turnover.

For a more accurate picture of the companies, Table 1 has been made. This proves that among the companies that have been on the market for less than 10 years, almost $90 \%$ have an annual turnover of less than one million euros, the figures are declining as we increase the period of existence on the market, respectively $63.6 \%$, between 10 and 20 years and $58.3 \%$, between 21 and 30 years.

Table 1. How long has your company been operating? * What is the company's annual turnover?

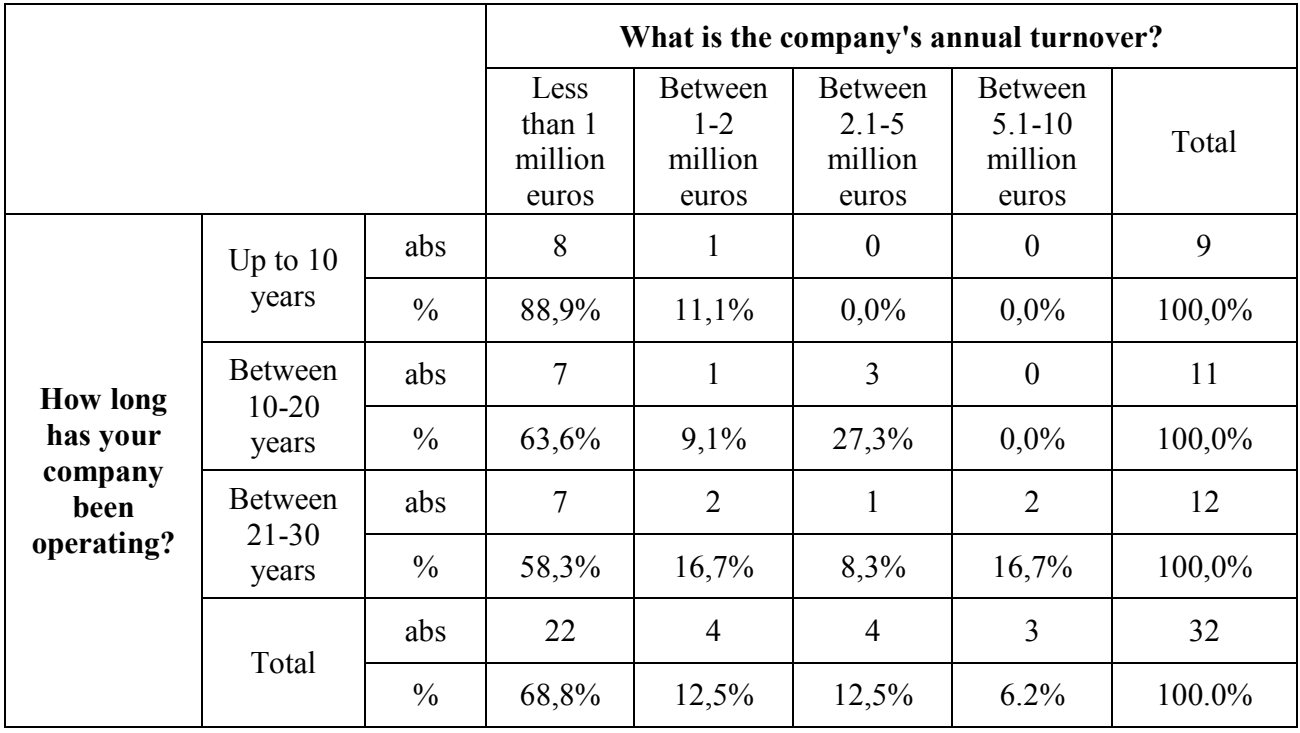

Regarding the number of managers in Hunedoara companies, in proportion of almost two thirds $(65.6 \%)$ they have only one manager, and the rest of over a third $(34.4 \%)$ between one and three managers (Fig. 3). 


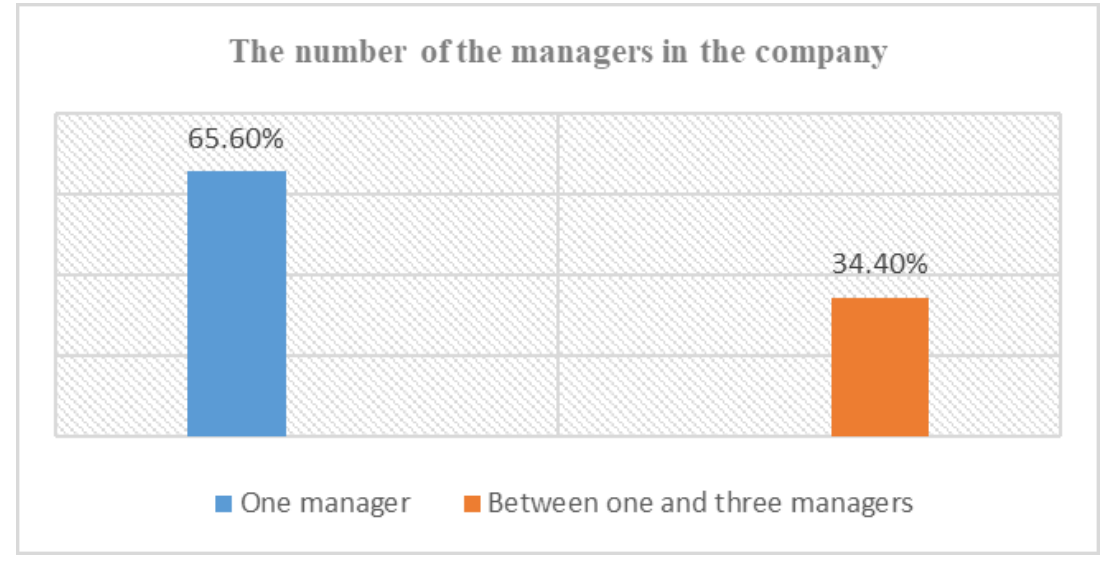

Fig. 3. The number of the managers in the company.

For almost $80 \%$ of the respondents, the managerial communication is exercised by the general manager. Only $6.3 \%$ say that the first three managers exercise managerial communication and $15.6 \%$ claim that each manager exercises communication in his department (Fig. 4). No respondent leaves the exercise of managerial communication to the manager or communication specialist.

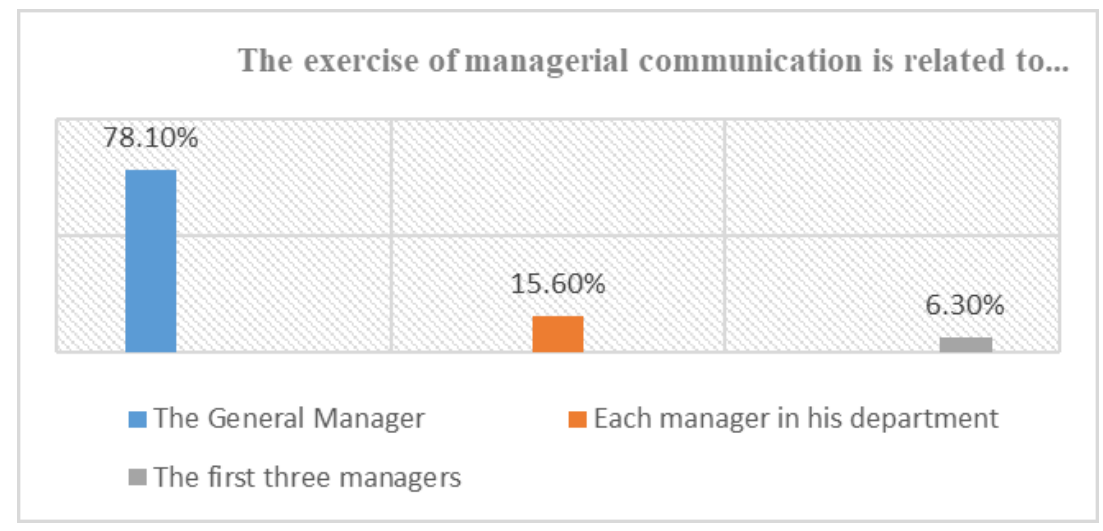

Fig. 4. The exercise of managerial communication is related to ...

Table 2 reveals that, in over $90 \%$ of companies with a turnover of less than one million euros, managerial communication is exercised by the general manager. This percentage decreases to $75 \%$ in companies with a turnover between one million and two million euros and to $50 \%$ in the case of companies with a turnover between 2.1 and 5 million euros. It should be noted that the other $25 \%$ and $50 \%$, respectively, do not go to the first three managers, or to the department managers.

The situation is completely different in the case of companies with an annual turnover between 5.1 and 10 million euros. Here the managerial communication is no longer exercised at all by the general manager but is divided equally between the first three managers and the department managers.

The connection between managerial communication and company success is a theme itself. The influence of the company's success by communication is appreciated "largely" by half of the respondents. The others consider that the influence is only "appropriately" (Fig. 5). 
Table 2. What is the company's annual turnover? * Managerial communication is exercised by ...

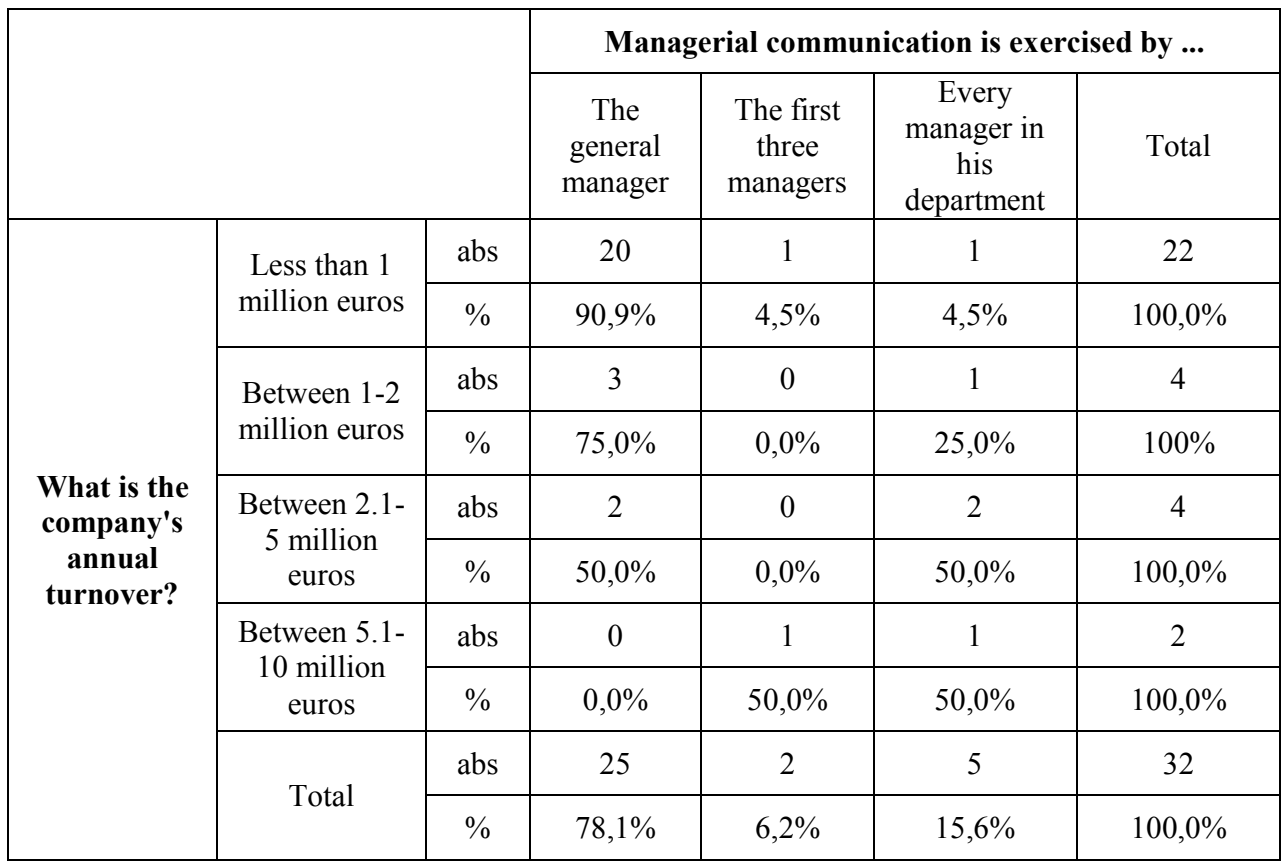

No respondent chose the options "to a small extent" or "not at all", which shows that the respondents of this research are aware of the benefits of managerial communication (Fig. $5)$.

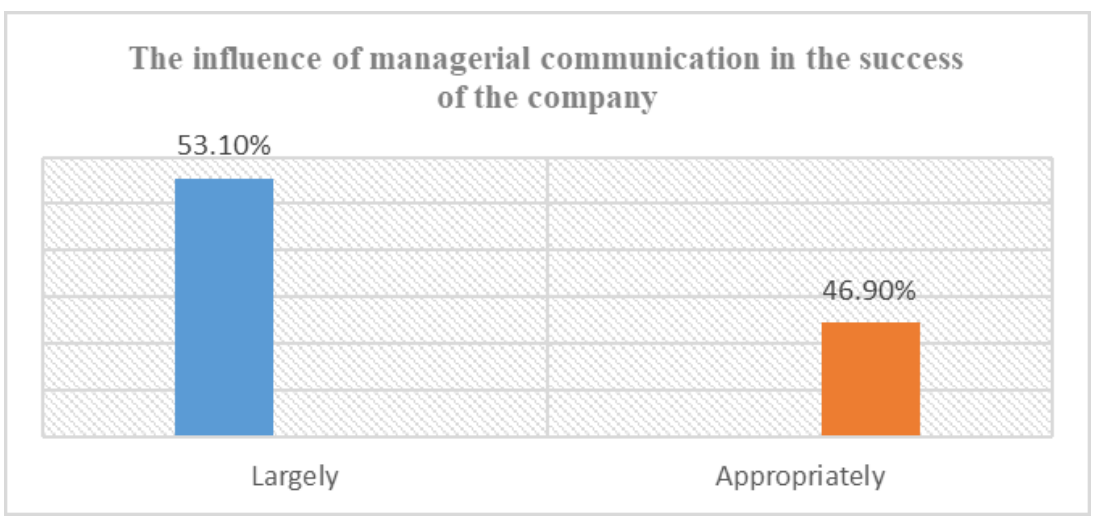

Fig. 5. The influence of managerial communication in the success of the company.

The data presented in Table 3 are very eloquent. It can be seen that the $66.7 \%$ of company managers of companies with an annual turnover of less than one million euros claim that communication largely influences the company's success. These are followed in proportion of $13.3 \%$ by the managers of companies with turnovers between 1 and two million euros, respectively between 2.1 and 5 million euros. The lowest share of $6.7 \%$ is in the case of companies with turnovers between 5.1 and 10 million euros. The influence of communication on the company's success is considered "adequately" by over $70 \%$ of managers of companies with annual turnover of less than one million euros, $11.8 \%$ of managers of companies with revenues between 1 and two million between 2.1 and 5 
million. The lowest percentage of $5.9 \%$ is found in the managers of companies with turnovers between 5.1 and 10 million euros.

Table 3. Does managerial communication influence the success of your company? * What is the company's annual turnover?

\begin{tabular}{|c|c|c|c|c|c|c|c|}
\hline & \multicolumn{5}{|c|}{ What is the company's annual turnover? } \\
\hline & & & $\begin{array}{c}\text { Less } \\
\text { than } 1 \\
\text { million } \\
\text { euros }\end{array}$ & $\begin{array}{c}\text { Between } \\
1-2 \\
\text { million } \\
\text { euros } \\
\end{array}$ & $\begin{array}{c}\text { Between } \\
2.1-5 \\
\text { million } \\
\text { euros } \\
\end{array}$ & $\begin{array}{c}\text { Between } \\
5.1-10 \\
\text { million } \\
\text { euros } \\
\end{array}$ & Total \\
\hline \multirow{6}{*}{$\begin{array}{c}\text { Does } \\
\text { managerial } \\
\text { communica } \\
\text { tion } \\
\text { influence } \\
\text { the success } \\
\text { of your } \\
\text { company? }\end{array}$} & \multirow[b]{2}{*}{ Largely } & abs & 10 & 2 & 2 & 1 & 15 \\
\hline & & $\%$ & $66,7 \%$ & $13,3 \%$ & $13,3 \%$ & $6,7 \%$ & $100,0 \%$ \\
\hline & \multirow{2}{*}{$\begin{array}{l}\text { Appropriat } \\
\text { ely }\end{array}$} & abs & 12 & 2 & 2 & 1 & 17 \\
\hline & & $\%$ & $70,6 \%$ & $11,8 \%$ & $11,8 \%$ & $5,9 \%$ & $100,0 \%$ \\
\hline & \multirow{2}{*}{ Total } & abs & 22 & 4 & 4 & 2 & 32 \\
\hline & & $\%$ & $68,8 \%$ & $12,5 \%$ & $12,5 \%$ & $6,2 \%$ & $100,0 \%$ \\
\hline
\end{tabular}

\section{Conclusions}

It can be concluded that there are differences in the communication approach to between managers of small or large companies. The general managers of small companies, with a turnover of less than two million euros per year, focus managerial communication around them, although they are aware that the influence of communication on the success of the company is considerable. In large companies, with an annual turnover between 5.1 and 10 million euros, general managers leave managerial communication to subordinate managers and those in departments and do not even consider the influence of communication on the success of the company.

Therefore, to grow and indirectly develop managerial communication, managers of small companies, which are very often the owners of these companies, and whose proportion is overwhelming in the market, are in dire need of a decentralization of communication, to delegate these responsibilities to others. Specifically, the responsibility for managerial communication must be passed on to a specialist or one or more lower-level managers. Such a delegation of the responsibility of managerial communication creates the premises for an increase in the turnover of companies with a turnover of less than two million euros per year in the higher category, i.e., of companies with an annual turnover between 2.1 and 5 million euros per year.

Achieving such a goal could also have valences at the level of mentality, managing to break the communist saying according to which "the boss knows everything", i.e., he has expertise in any field, from business management to communication management.

Changing the mentality of managers, moving to an improved perspective on managerial communication and business in general is the necessary step to change the paradigm needed by both the business environment and Romanian society in general.

\section{References}

1. B. van Ruler, D. Verčič, Public Relations and Communication Management in Europe (Mouton de Gruyter, Berlin/New York, 2004) 
2. G. Adler, Financial Times Briefing on Management Communication (Pearson Education Ltd., Edinburgh, 2011)

3. V. Păuş, Communication and human resources (Bucharest, 2012)

4. B. Miege, The conquered communication society (Polirom, Iași, 2000)

5. P. Bâzu, Managerial Communication (Rovimed Pub., Bacău, 2010)

6. M. Pikhart, B. Klimova, Information 11(6), 336 (2020)

7. J.K.C. Chen, T. Sriphon, Perspective on COVID-19 Pandemic Factors Impacting Organizational Leadership, Sustainability 13, 3320 (2021)

8. Nationally representative employers' confederation for SMEs, White Paper of SMEs in Romania 2020, Research report no. 18, Libris.ro, Bucharest, 16 (2021) Available: www.cnipmmr.ro 